
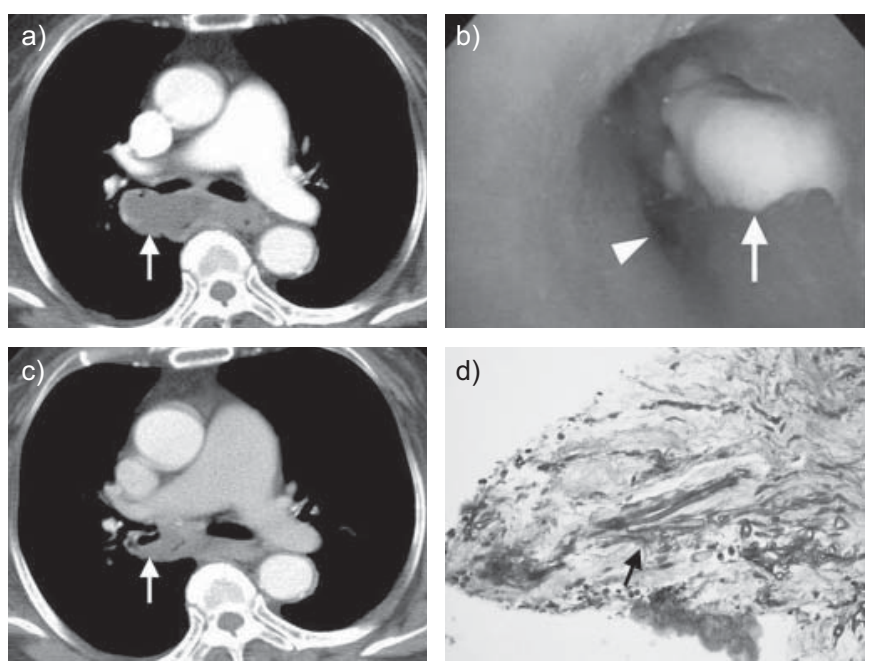

FIGURE 1. Mediastinal zygomycosis in a 76-yr-old diabetic female. a) The initial chest computed tomography (CT) scan showed a $5.7 \times 5.5 \times 3.7-\mathrm{cm}$ mass lesion with air density on the right hilum (arrow). b) Fibreoptic bronchoscopy revealed a wedge-shaped perforation on the membranous portion of the right main bronchus and whitish caseous tissue in the mediastinum (arrow). It was also noted that the narrowed intermediate bronchus was compressed by the mediastinal lesion (arrowhead). c) After antifungal treatment for 2 months, repeated CT revealed a decrease in the size of the mediastinal mass (arrow). d) Periodic acid-Schiff-stained mediastinal tissue section showed broad, pauciseptate hyphae with branches at right angles (arrow) within necrotic tissue. Magnification: 200x.

because macrophages in diabetic hosts are impaired in the suppression of spore germination [9]. Because zygomycosis has the characteristic features of angioinvasion, vascular thrombosis and tissue necrosis [10], mediastinal zygomycosis may erode into the adjacent bronchus and produce a bronchial perforation. Though the second mechanism is a more reasonable explanation for the presentation in this case, further studies are still needed for confirmation.

Based on an early diagnosis and reversal of the underlying predisposing condition, this patient with subacute presentation of mediastinal zygomycosis was treated successfully with $\mathrm{AMB}$ and L-AMB. Along with histoplasmosis and tuberculosis, zygomycosis should be considered in patients with clinical manifestations of chronic mediastinitis and bronchial perforations.
H-C. Liu*\#, M-S. Jan ", Y-C. Lin", W-L. Lin", T-C. Wu* C-N. Huang ${ }^{\S}, \mathrm{C}-\mathrm{M}$. Chen ${ }^{\#}$ and M-C. Lu ${ }^{\top f}$

*Division of Chest Medicine, ${ }^{5}$ Division of Endocrinology and Metabolism, ${ }^{f}$ Division of Infectious Diseases, Dept of Internal Medicine, Chung Shan Medical University Hospital, "Dept of Microbiology and Immunology, Chung Shan Medical University, "Dept of Life Sciences, National Chung-Hsing University, and 'Dept of pathology, Chung Shan Medical University Hospital, Taichung, Taiwan.

Correspondence: M-C. Lu, Dept of Internal Medicine, ChungShan Medical University Hospital, No. 110, Section 1, Jian-Guo North Road, Taichung, Taiwan. E-mail: yokoki2@gmail.com

Statement of Interest: None declared.

\section{REFERENCES}

1 Roden M, Zaoutis $\mathrm{T}$, Buchanan $\mathrm{W}$, et al. Epidemiology and outcome of zygomycosis: a review of 929 reported cases. Clin Infect Dis 2005; 41: 634-653.

2 Lee FY, Mossad SB, Adal KA. Pulmonary mucormycosis: the last 30 years. Arch Intern Med 1999; 159: 1301-1309.

3 Seo JB, Song KS, Lee JS, et al. Broncholithiasis: review of the causes with radiologic-pathologic correlation. Radiographics 2002; 22: S199-S213.

4 Marwaha RK, Banerjee AK, Thapa BR, et al. Mediastinal zygomycosis. Postgrad Med J 1985; 61: 733-735.

5 Robertson B, Bautista M, Russell T, et al. Fibrosing mediastinitis secondary to zygomycosis in a twenty-two-month-old child. Pediatr Infect Dis J 2002; 21: 441-442.

6 Connor B, Anderson R, Smith J. Mucor mediastinitis. Chest 1979; 75: 525-526.

7 Leong AS. Granulomatous mediastinitis due to Rhizopus species. Am J Clin Pathol 1978; 70: 103-107.

8 Husari AW, Jensen WA, Kirsch CM, et al. Pulmonary mucormycosis presenting as an endobronchial lesion. Chest 1994; 106: 18891891.

9 Levitz SM, Selsted ME, Ganz T, et al. In vitro killing of spores and hyphae of Aspergillus fumigatus and Rhizopus oryzae by rabbit neutrophil cationic peptides and bronchoalveolar macrophages. J Infect Dis 1986; 154: 483-489.

10 Ribes JA, Vanover-Sams CL, Baker DJ. Zygomycetes in human disease. Clin Microbiol Rev 2000; 13: 236-301.

DOI: $10.1183 / 09031936.00155110$

\title{
Pulmonary endarterectomy in sickle cell haemoglobin C disease
}

\section{To the Editors:}

Pulmonary hypertension $(\mathrm{PH})$ is a common complication of sickle cell disease (SCD), with a prevalence of $10-20 \%$, and is often a cause of death in this patient population [1]. PH can be related to two different mechanisms: 1) chronic haemolysis with endothelial dysfunction, reduction in nitric oxide bioavailability and subsequent proliferative vasculopathy; or 2) vaso-occlusive complications resulting from erythrocyte sickling and hyperviscosity [2]. According to a recent report, up to $23 \%$ of SCD patients with $\mathrm{PH}$ have evidence of perfusion 
mismatch on ventilation/perfusion scan and $11.5 \%$ have evidence of chronic thromboembolic disease on computed tomography (CT) pulmonary angiograms [3]. Although pulmonary endarterectomy (PEA) is the best option for patients with $\mathrm{PH}$ related to chronic thromboembolic disease, chronic haemolysis with subsequent proliferative vasculopathy in the distal vessels put patients with SCD at increased risk of residual $\mathrm{PH}$ after PEA. In addition, SCD patients may be at increased risk of developing in situ thrombosis in the proximal vessels which can be difficult to differentiate from true thromboembolic events on radiological imaging.

Herein, we present the case of a patient with SCD due to sickle cell haemoglobin $(\mathrm{Hb}) \mathrm{C}$ disease (HbSC) and chronic thromboembolic pulmonary hypertension (CTEPH) who underwent successful PEA with complete normalisation of the pulmonary haemodynamics after surgery. This patient presented with several complications of erythrocyte sickling and hyperviscosity, but had no evidence of haemolytic anaemia, supporting the possibility that PEA may be particularly helpful in SCD patients developing $\mathrm{PH}$ as a consequence of erythrocyte sickling and hyperviscosity rather than chronic haemolysis.

A 52-yr-old male with HbSC and protein S deficiency in New York Heart Association (NYHA) class III was diagnosed with CTEPH. His history revealed episodes of acute chest syndrome, bone pain crisis and retinopathy, but no history of priapism, leg ulcers or stroke. Blood electrophoresis revealed $\mathrm{Hb}$ of $118 \mathrm{~g} \cdot \mathrm{L}^{-1}, \mathrm{HbS} 51 \%, \mathrm{HbC} 46 \%, \mathrm{HbA}_{2} 3 \%$ and normal $\mathrm{HbF}$. Abdominal CT identified splenic atrophy and renal wedge infarcts with an elevated serum creatinine of $144 \mu \mathrm{mol} \cdot \mathrm{L}^{-1}$. His blood analysis showed no evidence of haemolytic activity with normal lactate dehydrogenase, reticulocyte count and bilirubin.

\begin{tabular}{|c|c|c|}
\hline & Before surgery & After surgery \\
\hline \multicolumn{3}{|l|}{ Right heart catheterisation } \\
\hline Ppa,sys $\mathrm{mmHg}$ & 61 & 25 \\
\hline Ppa,dias $\mathrm{mmHg}$ & 34 & 8 \\
\hline $\bar{P}$ pa mmHg & 41 & 16 \\
\hline Cardiac index $\mathrm{mL} \cdot \mathrm{min}^{-1} \cdot \mathrm{m}^{-2}$ & 1.9 & 4.6 \\
\hline Total PVR dyn $\cdot \mathrm{s} \cdot \mathrm{cm}^{-5}$ & 924 & 136 \\
\hline \multicolumn{3}{|l|}{ 6-min walk test } \\
\hline Distance $\mathrm{m}$ & 465 & 578 \\
\hline Borg dyspnoea score & 10 & 0 \\
\hline Lowest saturation \% & 69 & 100 \\
\hline \multicolumn{3}{|l|}{ Echocardiogram } \\
\hline RV dysfunction & Severe & Mild \\
\hline $\mathrm{RV}$ size $\mathrm{cm}$ & 6.2 & 3.8 \\
\hline Ppa,sys $\mathrm{mmHg}$ & 81 & 32 \\
\hline Tricuspid regurgitation & Moderate & Trace \\
\hline \multicolumn{3}{|l|}{ Brain natriuretic peptide } \\
\hline Level $\mathrm{pg} \cdot \mathrm{mL}^{-1}$ & 426 & 13 \\
\hline
\end{tabular}

Ppa,sys: systolic pulmonary artery pressure; $P$ pa,dias: diastolic pulmonary artery pressure; $\bar{P}$ pa: mean pulmonary artery pressure; PVR: pulmonary vascular resistance; RV: right ventricle.
His pre-operative investigations are summarised in table 1 and figure 1 .

After a multidisciplinary discussion, the decision was made to proceed with PEA. A 20-U exchange transfusion was performed 4 days pre-operatively. After the exchange transfusion, blood electrophoresis showed $\mathrm{HbS} 14 \%, \mathrm{HbC} 13 \%$ and
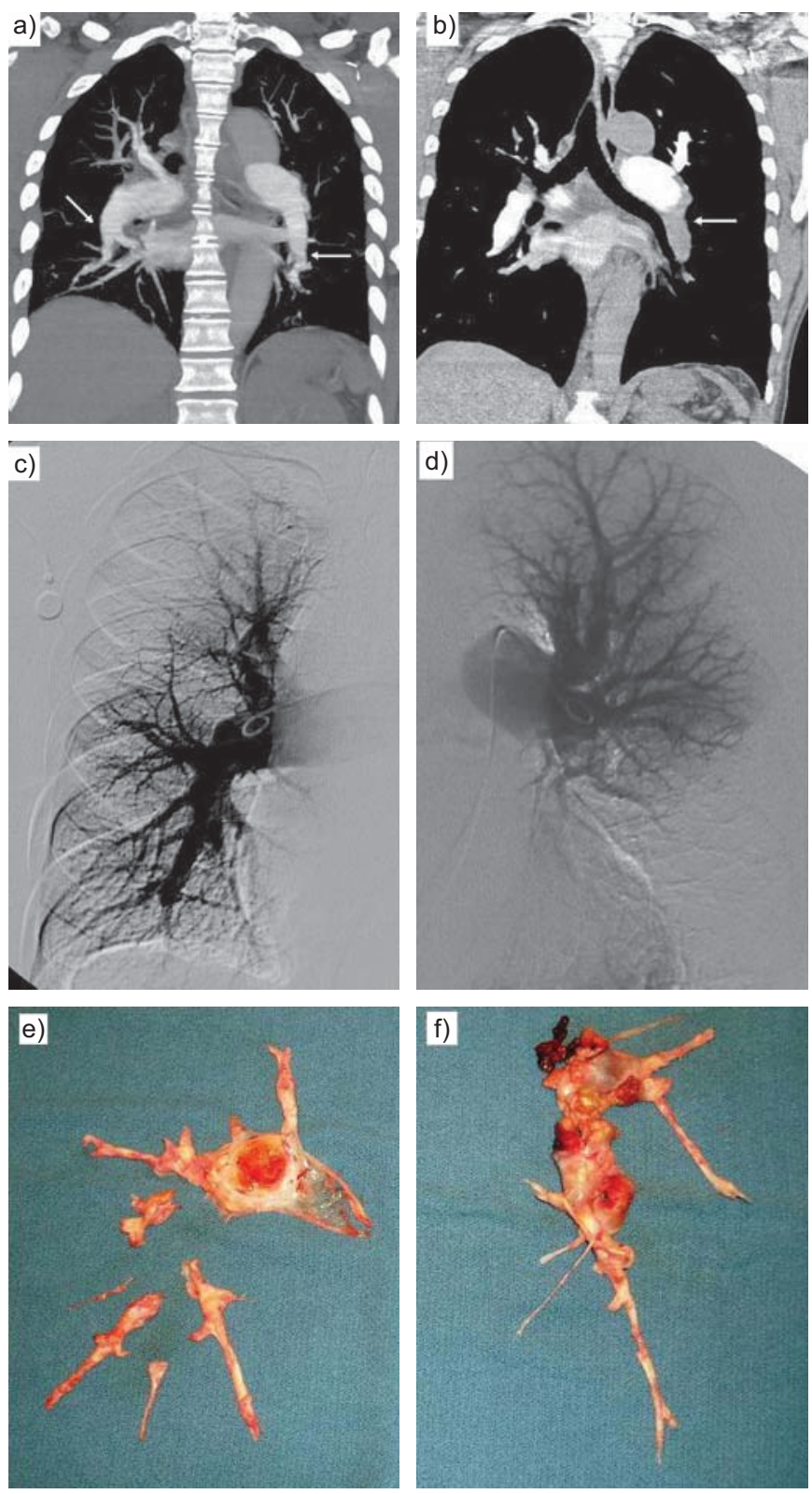

FIGURE 1. a) Computed tomography (CT) pulmonary angiogram showing evidence of webs in the descending branch of the right and left pulmonary artery (arrows). b) CT pulmonary angiogram performed $1 \mathrm{yr}$ later after referral to our centre, demonstrating the presence of new large thrombi in the left pulmonary artery (arrow) that occurred despite treatment with low molecular weight heparin. c) Pulmonary angiogram of the right pulmonary artery showing evidence of segmental defects in the right upper and lower lobes. d) Pulmonary angiogram of the left pulmonary artery showing an occlusion of the descending branch to the left lower lobe. e) Pulmonary endarterectomy specimen of the right lung. f) Pulmonary endarterectomy specimen of the left lung. 
$\mathrm{HbA} 71 \%$. On cardiopulmonary bypass (CPB), an additional $1 \mathrm{~L}$ of blood was exchanged with $2 \mathrm{U}$ of packed red cells and haematocrit was reduced to $\sim 25 \%$. Blood electrophoresis performed after this second exchange revealed $\mathrm{HbS} 13 \%$ and $\mathrm{HbC} 12 \%$. The patient was cooled to $18^{\circ} \mathrm{C}$. Blood gases were managed using $\alpha$-stat. Successful PEA of the right and left pulmonary artery was performed with two circulatory arrests totalling $32 \mathrm{~min}$ (fig. 1). The patient was rewarmed to a core temperature of $37^{\circ} \mathrm{C}$ and weaned easily from $\mathrm{CPB}$. Total $\mathrm{CPB}$ and cross-clamp times were 239 and $107 \mathrm{~min}$, respectively. The patient was extubated on the first post-operative day and discharged from hospital on the sixth post-operative day. After PEA, the patient presented with complete normalisation of his pulmonary haemodynamics and remained in NYHA class I 15 months after surgery (table 1).

This case demonstrates that normalisation of pulmonary haemodynamics is possible after PEA in patients with SCD. Our patient had a diagnosis of $\mathrm{HbSC}$ and presented with typical complications of hyperviscosity (acute chest syndrome, bone pain crisis and retinopathy) and no evidence of haemolytic anaemia [2]. The higher frequency of complications from hyperviscosity in patients with $\mathrm{HbSC}$ supports the notion that $\mathrm{PH}$ may be more frequently related to local thrombosis and embolic events than to a proliferative vasculopathy related to haemolytic anaemia in this subgroup of patients with SCD disease. The presence of an atrophic spleen may also have been a potential risk factor for the development of CTEPH in our patient $[4,5]$. However, the results of PEA in patients with previous splenectomy may carry increased risk of residual $\mathrm{PH}$ after surgery due to the presence of thromboembolic disease in the small pulmonary arteries $[5,6]$.

Patients with SCD are at risk of sickling crisis during deep hypothermic circulatory arrest (DHCA) because of hypothermia, hypoxia, acidosis and low-flow states. Although there is no consensus on absolute safe values of $\mathrm{HbS}$ in patients undergoing surgery, it is proposed that the level of $\mathrm{HbS}$ should be reduced to $<30 \%$ for major surgical procedures and $<10 \%$ for patients undergoing cardiac surgery [7]. As shown in this case and in an additional three cases reported in the literature, PEA is possible under DHCA after exchange transfusion if $\mathrm{HbS}$ is reduced to $\sim 10 \%$ [8, 9]. During $\mathrm{CPB}$, particular attention should be paid to maintain good flows to limit end organ ischaemia, maintain normal acid-base status and limit the duration of circulatory arrest periods. The use of a cell saver is controversial, but filtered and washed blood from the cell saver system may be more prone to sickling and was, therefore, not used in our patient.

In conclusion, the current report supports the feasibility of PEA under DHCA in patients with SCD. This case also demonstrates that normalisation of the pulmonary haemodynamics is possible after PEA in patients with SCD. Hence, a thorough evaluation for potentially curable (i.e. by surgery) chronic thromboembolic disease should be undertaken for all patients presenting with $\mathrm{PH}$, irrespective of the underlying disease.

\section{A. Jerath*, P. Murphy*, M. Madonik* , D. Barth ${ }^{\text {, J J. Granton }}{ }^{+}$ and M. de Perrot ${ }^{\S}$}

Depts of *Anesthesia, "Perfusion Medicine, "Hematology, ${ }^{+}$Respirology, and ${ }^{\S}$ Thoracic Surgery, Toronto Pulmonary Endarterectomy Program, University of Toronto, Toronto, ON, Canada.

Correspondence: M. de Perrot, Toronto Pulmonary Endarterectomy Program, Toronto General Hospital, 9N-961, 200 Elizabeth Street, Toronto, M5G 2C4 ON, Canada. E-mail: marc.deperrot@uhn.on.ca

Statement of Interest: None declared.

Acknowledgements: The authors would like to thank K.M. Kerr and G.R. Manecke from the University of California in San Diego (San Diego, CA, USA) for their advice in planning the surgery for this patient.

\section{REFERENCES}

1 Rees DC, Williams TN, Gladwin MT. Sickle-cell disease. Lancet 2010; 376: 2018-2031.

2 Kato GJ, Gladwin MT, Steinberg MH. Deconstructing sickle cell disease: reapprasisal of the role of haemolysis in the development of clinical subphenotypes. Blood Rev 2007; 21: 37-47.

3 Anthi A, Machado RF, Jlson ML, et al. Hemodynamic and functional assessment of patients with sickle cell disease and pulmonary hypertension. Am J Respir Crit Care Med 2007; 175: 1272-1279.

4 Bonderman D, Wilkens $\mathrm{H}$, Wakounig S, et al. Risk factors for chronic thromboembolic pulmonary hypertension. Eur Respir J 2009; 33: 325-331.

5 Jaïs X, Ioos V, Jardim C, et al. Splenectomy and chronic thromboembolic pulmonary hypertension. Thorax 2005; 60: 10311034.

6 Bonderman D, Skoro-Sajer N, Jakowitsch J, et al. Predictors of outcome in chronic thromboembolic pulmonary hypertension. Circulation 2007; 115: 2153-2158.

7 Firth PG, Head A. Sickle cell disease and anesthesia. Anesthesiology 2004; 101: 766-785.

8 Yung GL, Channick RN, Fedullo PF, et al. Successful pulmonary thromboendarterectomy in two patients with sickle cell disease. Am J Respir Crit Care Med 1998; 157: 1690-1693.

9 Vocelka CR, Lindley GG, Mulligan MS. Cardiopulmonary bypass with deep hypothermic circulatory arrest for a patient with sickle cell anemia: a case report. J Extracorp Technol 2001; 33: 243-244.

DOI: 10.1183/09031936.00192910 